\title{
Protective Effect of Recombinant Ganoderma Lucidum Immunomodulatory Protein (rLZ-8) Against Scopolamine- Induced Alzheimer's Disease in Rats
}

\author{
Haotian Wang \\ jlin university \\ Jun Fu \\ jlin university \\ Huan Tang \\ jilin university \\ Yan Li \\ jlin university \\ Liping Song \\ Jilin University \\ Dan Xu \\ Jilin University \\ Qiang Hao \\ Jilin University \\ Qianwen Li \\ Jlin University \\ Zhihui Ren \\ Jilin University \\ Xiaowei Zhou \\ Jilin University \\ Hongyu Chen \\ Jilin University \\ Weitao Zhao \\ Jilin University \\ Juan Jia \\ Jilin University \\ Fei Sun \\ Jilin University \\ Jin Pei ( $\square$ peijin@jlu.edu.cn ) \\ jlin university
}

\section{Research}

Keywords: rLZ-8, Scopolamine, Alzheimer disease, Morris water maze, Learning and memory

Posted Date: August 7th, 2020

DOI: https://doi.org/10.21203/rs.3.rs-47475/v1

License: (a) (i) This work is licensed under a Creative Commons Attribution 4.0 International License. Read Full License 


\section{Abstract}

Backgroud: Alzheimer's disease (AD) is one of the most common neurodegenerative diseases in the elderly, seriously threatening the health of the elderly. In this study, the protective effect of recombinant Ganoderma lucidum immunomodulatory protein (rLZ-8) against the scopolamine-induced Alzheimer's disease (AD) in rats was studied for the first time.

Methods: Male Wistar rats in rLZ-8-treated groups were intraperitoneally injected with $56 \mu \mathrm{g} / \mathrm{kg}, 112 \mu \mathrm{g} / \mathrm{kg}$, and $224 \mu \mathrm{g} / \mathrm{kg} \mathrm{rLZ}-8$, respectively, those in donepezil group were intraperitoneally injected with $1.0 \mathrm{mg} / \mathrm{kg}$ donepezil, and those in the normal saline group were intraperitoneally injected with an equal volume of normal saline, successively for 14 days. On the $7^{\text {th }}$ day after the administration, the learning and memory ability of rats was observed by Morris water maze test, and the biochemical indexes and cytokines in the serum and brain tissues of the rats were detected after the behaviour test for investigating the protective mechanism of rLZ-8 against the scopolamine-induced AD in rats.

Results: In the water maze test, compared with that in the model group, the escape latency and the swimming distance of rats on the $5^{\text {th }}$ and $6^{\text {th }}$ day were significantly shortened in the three rLZ-8-treated groups. In the space exploration test, compared with that in the model group, the number of passing through the location of original platform was significantly increased and the time of rats' staying in the second quadrant was significantly prolonged in the three rLZ-8-treated groups, and furthermore, the detectionresults related to Alzheimer's disease in the serum, hippocampus and cerebral cortex of ratsindicated that rLZ-8 could improve the contents or activities of the related indexes.

Conclusion: In rlZ-8 could significantly improve the learning and memory ability of AD rats, and the possible mechanism was to improve the learning and memory ability by protecting the cholinergic system.

\section{Backgroud}

Alzheimer's disease (AD), also known as senile dementia, is one the most common central nervous system degenerative diseases in the elderly. $A D$ is a heterogeneous disease with multi-pathogenesis, and its key symptom is progressive cognitive dysfunction, with characteristic changes in neuropathology and neurochemistry ${ }^{[1]}$. More and more evidences show that $\beta$ amyloid $(A \beta)$ is the common pathway of $A D$ induced by various causes, and the $\beta$-amyloid $(A \beta)$ is one of the key factors in the formation and development of $A D$, which can induce the apoptosis of neurons by bringing about inflammatory cascade reaction, triggering oxidative stress, interfering with in vivo balance of ions in neurons to cause the dysfunction of extensive neurons and neuraxons, and the death of nerve cells, leading to dementia. There is no specific treatment for AD so far, and it is treated primarily with the symptomatic therapy ${ }^{[2,3]}$, including acetylcholinesterase inhibitors, antioxidants, non-steroidal antiinflammatory drugs, receptor antagonists ${ }^{[4]}$, targeted drugs ${ }^{[5]}$, neuroprotective drugs ${ }^{[6]}$, etc. However, these drugs have showed many disadvantages, such as too short duration, more serious side effects and expensive price, so to look for drugs with the satisfied effect but less side effect is an important issue to be solved in the treatment of AD.

Ganoderma lucidum, a traditional Chinese medicine, has many pharmacodynamic activities ${ }^{[7,8]}$. At present, the research on the activity of ganoderma lucidum mainly focuses on the proteoglycan of Ganoderma lucidum, which can improve the oxygen supply ability of hemoglobin, reduce the useless consumption of oxygen, accelerate the blood circulation, and improve the oxygen supply and nutrition state of the brain, to make the brain in a good physiological state, with a certain effect on delaying aging ${ }^{[9]}$. Fungal Immunomodulatory Protein of Ganoderma lucidium (LZ-8) was the first fungal immunomodulatory protein isolated from the mycelium of Ganoderma lucidum by Japanese scientists ${ }^{[10]}$, with a molecular weight of $12.4 \mathrm{kDa}$ and isoelectric point of 4.4 , consisting of 110 amino acids and containing $1.3 \%$ sugar. LZ-8 can promote the proliferation of peripheral lymphocytes and spleen cells, induce macrophages of animals and human to secrete a variety of cytokines, then the LZ-8 can prevent and eliminate the invasion of pathogens, so as to maintain the health of the body. A large-scale expression system of Ganoderma lucidum immunomodulatory protein in Pichia pastoris was established for the first time and a highly purified Ganoderma lucidum immunomodulatory protein was obtained ${ }^{[11]}$, and multiple pharmacodynamic activities of Ganoderma lucidum immunoregulatory protein were found in our previous studies ${ }^{[12-15]}$ Learning and memory are closely associated with the cholinergic system in basal forebrain (BF), and one of the reasons for the decline of learning and memory

Page 2/21 
ability is the degeneration of cholinergic neurons in BF. The molecular formula of L-scopolamine is $\mathrm{C}_{17} \mathrm{H}_{21} \mathrm{NO}_{4}$, that it is a scopolamine-type alkaloid and one of the strongest pharmacological agents in belladonna, and it can be used to block parasympathetic nerve and also used as a central nervous system inhibitor. Scopolamine blocks the binding of postsynaptic acetylcholine to its receptors by competitively binding to $M$ receptors in the central nervous system to reduce the role of acetylcholine associated with learning and memory, inducing the AD animal model with learning and memory impairment ${ }^{[16,17]}$, and the model as one of the commonly used $A D$ models has been widely used in the experiment of drugs used for the treatment of $A D$.

Based on the previous studies, the effect of recombinant Ganoderma lucidum immunomodulatory protein (rLZ-8) on the learning and memory ability of rats with $A D$, and its underlying mechanisms were investigated in this study, which may provide a basis for the development of drugs for the treatment of $A D$.

\section{Materials And Methods}

\section{Materials}

Animals: Healthy and active clean-grade male Wistar rats, weighing from 250 to $300 \mathrm{~g}$, were purchased from Animal Center of Bethune Medical College of Jilin University, and the animal license No. was SCXK- (Ji) 2007/0003.

Reagents: rLZ-8 was prepared by author's Lab. Scopolamine hydrobromide was the product of Shanghai Hefeng Pharmaceutical Co., Ltd (batch number: 120501, China). Aricept (Donepezil) was manufactured by Weicai (China) Pharmaceutical Co., Ltd. Picric acid was purchased from Shanghai Sinopharm Company Limited (China). Acetylcholinesterase (TChE), choline acetyltransferase (ChAT), monoamine oxidase (MAO), superoxide dismutase (SOD), glutathione peroxidase (GSHPX),malondialdehyde (MDA) and Coomassie brilliant blue assay kits were purchased from Nanjing Jiancheng Bioengineering Institute (China). Elisa kits were purchased from RD Company (USA).

\section{Methods}

\section{Animal Grouping}

After they were acclimatized to the laboratory environment for a week, 60 rats were randomly divided into 6 groups, namely normal saline group, AD model group, donepezil group, $56 \mu \mathrm{g} / \mathrm{kg}$ rLZ-8 group, $112 \mu \mathrm{g} / \mathrm{kg}$ rLZ-8 group, and $224 \mu \mathrm{g} / \mathrm{kg}$ rLZ-8 group, 10 rats in each group.

\section{Drug Administration and Animal Model Preparation}

Rats in the normal saline group and model group were intraperitoneally injected with saline twice a day, at 8:00 and 16:00, respectively, successively for 14 days (day1-day14), those in donepezil group (P) were administrated intragastrically with 1.0 $\mathrm{mg} / \mathrm{kg}$ donepezil at 8:00 once a day, successively for 14 days (day1-day14), and those in the three rLZ-8 groups were intraperitoneally injected with the corresponding doses of rLZ-8 twice a day at 8:00 and 16:00, respectively, successively for 14 days (day1-day14). Except those in the saline group, all rats in the other groups were intraperitoneally injected with $1.5 \mathrm{mg} / \mathrm{kg}$ scopolamine hydrobromide at 10:00 once a day, successively from day 8 to day14 (day8-day14).

\section{Observation Indexes}

3.1 Physical observation: The body weight of rats was weighed with a balance and recorded every day. The state of the rats was observed twice a day in the morning and afternoon, respectively, including the hair color, eating, defecation, movement, and sensitivity of rats.

3.2 Morris water maze test: Morris water maze test was used to evaluate the learning and memory of rats, lasting 7ds. Training test: The training test lasted 6 days and all rats were trained four times a day, in which the rats were placed into the water at the different entry water points each time for observing the escape latency, that is, the time required for the rats to climb the platform from the time when they were placed into the water within 120 s, and the rats were allowed to stay on the platform for $10 \mathrm{~s}$; if the 
rats did not find the platform within 120 s, the experimenter guided them to stay on the platform for 10 s, and the escape latency was recorded as 120s; the swimming distance of rats' from the entry water points to finding the platform was recorded as swimming distance. Space exploration test: On the $7^{\text {th }}$ day of the test, the platform was removed for observing the number of times that the rats swam over the original platform, the time of swimming in the original place where the platform was placed, and the steering angle of rats. Each space exploration test lasted $120 \mathrm{~s}$, in which the latency for the rats to find the original place, the swimming distance for the rats to swim to the original place and the times of rats' swimming across the original place were recorded as their memory results.

3.3 Detection of biochemical indexes: The rats were anesthetized with chloral hydrate immediately after the Morris water maze test. After the blood samples were taken from their abdominal aorta, their whole brain, hippocampus and cerebral cortex samples were taken immediately, and then the heart, liver, spleen, lung, kidney and thymus were taken rapidly. The blood sample was centrifuged at $3000 \mathrm{rpm}$ for 10 minutes to obtain the supernatants, and the serum acetylcholinesterase (AchE), monoamine oxidase (MAO), superoxide dismutase (SOD) and glutathione peroxidase (GSH-PX) activities, and malondialdehyde (MDA) contents were detected according to the instructions of assay kits. After weighing, the hippocampus and cerebral cortex were added with normal saline at the volume ratio of 1:9 and homogenized to be prepared into the homogenates, and then the homogenates were centrifuged at 2,500 rpm for 15 minutes to obtain the supernatants. the AchE, SOD, GSH-PX and choline acetyltransferase (ChAT), catalase (CAT), ATP enzyme, nitric oxide synthase activities, and MDA, tumor necrosis factor-a (TNF-

a), interleukin-6 (IL-6), interleukin- $\beta$ (IL-1 $\beta$ ), glial-derived neurotrophic factor (GDNF) and brain-derived neurotrophic factor (BDNF) contents in the supernatants were detected by following the instructions of the kits. The body weights and organ weights of rats were also weighed, respectively, for the calculation of their organ indexes.

\section{Statistical Analysis}

The data were statistically analyzed using SPSS16.0 and expressed as means $\pm S D(x \pm S)$. The difference between two groups was compared by $t$-test and $P<0.05$ was considered significant.

\section{Results}

1.Physical observation and the Changes in body weights The observation on the state of rats in the morning and evening showed that there was no significant difference in the hair gloss, basic eating condition and defecation between the normal saline group and the other experimental groups, and the movement and activity of rats in the other groups were slightly poorer than those in the normal saline group, but there was no significant difference in them between normal saline group and the other groups $(P \otimes 0.05)$.

During the experiment, the body weight of all rats in each group increased in varying degrees, and there was no difference in it among the groups (Figure 1.), indicating that scopolamine hydrobromide and rLZ-8 should have no effect on the body weight of rats.

\section{Morris water maze test}

\subsection{Training experiment}

2.1.1 In the training experiment of Morris water maze test, the rats in the other groups except the normal saline group were given scopolamine hydrobromide $30 \mathrm{~min}$ after the administration of rLZ-8 from the $8^{\text {th }}$ day to $14^{\text {th }}$ day of experiment, and the water maze test was performed $30 \mathrm{~min}$ after the administration of scopolamine hydrobromide. the escape latency of reaching to the platform of rats in rLZ-8 groups, donepezil group and AD model group were significantly longer than those in the normal saline group $(P<0.05)$ on the 5 th and 6 th day. As shown in Table 1. 
Table 1.

Escape latencies of rats in the training experiment of Morris water maze test $(s, x \pm s)$

\begin{tabular}{|c|c|c|c|c|c|c|}
\hline \multirow[t]{2}{*}{ Time (day) } & \multicolumn{6}{|c|}{ Groups $(n=10)$} \\
\hline & N.S & AD model & Donepezil & $56 \mu \mathrm{g} / \mathrm{kg}$ rLZ-8 & $112 \mu \mathrm{g} / \mathrm{kg}$ rLZ-8 & 224 pg/kg rLZ-8 \\
\hline 1 & $43.2 \pm 42.58$ & $105.9 \pm 24.48^{\star}$ & $110.3 \pm 20.11^{*}$ & $101.2 \pm 32.73^{\star}$ & $96.8 \pm 42.04^{*}$ & $106.8 \pm 21.93^{*}$ \\
\hline 2 & $24.3 \pm 31.97$ & $102.3 \pm 31.97^{*}$ & $100.2 \pm 28.58^{\star}$ & $103.0 \pm 33.56^{*}$ & $95.1 \pm 41.14^{\star}$ & $91.6 \pm 40.89^{\star}$ \\
\hline 3 & $20.2 \pm 23.18$ & $95.3 \pm 9.51^{*}$ & $92.4 \pm 28.24^{\star}$ & $96.1 \pm 24.45^{\star}$ & $83.1 \pm 15.08^{\star}$ & $79.4 \pm 20.79^{\star}$ \\
\hline 4 & $10.8 \pm 9.51$ & $92.1 \pm 19.51^{*}$ & $84.5 \pm 14.46^{*}$ & $88.8 \pm 15.69^{*}$ & $75.4 \pm 10.57^{\star}$ & $87.0 \pm 18.38^{*}$ \\
\hline 5 & $11.9 \pm 9.64$ & $99.4 \pm 8.51^{*}$ & $46.0 \pm 12.46^{\star \rrbracket}$ & $56.2 \pm 7.08^{* \square}$ & $67.8 \pm 12.09^{\star \rrbracket}$ & $80.9 \pm 8.03^{* \square} \triangle \triangle \boldsymbol{\Lambda}$ \\
\hline 6 & $8.9 \pm 6.60$ & $92.1 \pm 9.51^{*}$ & $43.8 \pm 11.86^{\star}$ & $45.9 \pm 12.60^{\star} \square$ & $64.7 \pm 9.57^{\star} \triangle \triangle$ & $81.4 \pm 5.27^{\star} \triangle \triangle \triangle \Delta \Delta$ \\
\hline \multicolumn{7}{|c|}{$\begin{array}{l}{ }^{\square} \text { Compared with the model group, } P<0.05 ;{ }^{\square} \text { Compared with the model group, } P<0.01 . \triangle \text { Compared with donepezil group, } \\
P<0.05 ; \triangle \triangle \text { Compared with donepezil group, } P<0.01 \text {. } \Delta \text { Compared with } 56 \mu \mathrm{g} / \mathrm{kg} \mathrm{rLZ-8} \text { group, } P<0.05 ; \Delta \Delta^{\wedge} \text { Compared with } \\
56 \mu \mathrm{g} / \mathrm{kg} \text { rLZ-8 group, } P<0.01 \text {. }\end{array}$} \\
\hline
\end{tabular}

2.1.2 In the training experiment of Morris water maze test, the rats in the other groups except the normal saline group were given scopolaminehydrobromide $30 \mathrm{~min}$ after the administration of rLZ-8 from the 8th day to 14 th day of experiment, and the water maze test was performed $30 \mathrm{~min}$ after the administration of scopolamine hydrobromide. the swimming distance of rats in rLZ-8 groups, donepezil group and AD model group were significantly longer than those in the normal saline group $(P<0.05)$. As shown in Table 2.

Table 2.

Swimming distance results of rats in the training experiment of Morris water maze test $(s, x \pm s)$

\begin{tabular}{|c|c|c|c|c|c|c|}
\hline \multirow{2}{*}{$\begin{array}{l}\text { Time } \\
\text { (day) }\end{array}$} & \multicolumn{6}{|l|}{ Groups $(n=10)$} \\
\hline & Normal saline & AD model & Donepezil & $56 \mu \mathrm{g} / \mathrm{kg}$ rLZ-8 & $\begin{array}{l}112 \mu \mathrm{g} / \mathrm{kg} \mathrm{rLZ}- \\
8\end{array}$ & 224 нg/kg rLZ-8 \\
\hline 1 & $1144.3 \pm 1045.5$ & $3460.4 \pm 905.5^{\star}$ & $3662.3 \pm 841.6^{*}$ & $3472.1 \pm 1173.2^{*}$ & $3026.4 \pm 1048.4^{*}$ & $3873.8 \pm 998.4^{*}$ \\
\hline 2 & $646.0 \pm 726.6$ & $3620.5 \pm 837.0^{*}$ & $3609.1 \pm 1173.6^{*}$ & $3726.6 \pm 1393.5^{\star}$ & $3290.9 \pm 1445.3^{*}$ & $3584.8 \pm 1637.8^{*}$ \\
\hline 3 & $520.4 \pm 562.2$ & $3289.3 \pm 632.0^{*}$ & $3192.0 \pm 905.1^{*}$ & $3473.8 \pm 1195.2^{*}$ & $2974.4 \pm 1652.3^{*}$ & $3012.3 \pm 1965.2^{*}$ \\
\hline 4 & $294.3 \pm 24.3$ & $2939.2 \pm 435.7^{\star}$ & $3082.9 \pm 725.2^{*}$ & $3231.4 \pm 684.3^{*}$ & $2709.2 \pm 885.2^{*}$ & $3028.6 \pm 918.6^{*}$ \\
\hline 5 & $315.3 \pm 237.6$ & $2907.3 \pm 235.8^{*}$ & $1519.4 \pm 413.9^{*}$ & $2069.9 \pm 774.7^{\star[}$ & $2235.9 \pm 783.8^{* \rrbracket}$ & $3006.3 \pm 812.5^{\star \square} \Delta \triangle \boldsymbol{\Delta}$ \\
\hline 6 & $259.9 \pm 173.8$ & $3010.5 \pm 470.1^{*}$ & $1541.2 \pm 106.7^{* \square}$ & $1483.1 \pm 364.5^{\star \square}$ & $2174.7 \pm 630.7^{\star[]}$ & $2913.8 \pm 620.2^{\star \star \Delta} \Delta \triangle \Delta \Delta$ \\
\hline
\end{tabular}


The rats in the other groups except the normal saline group were given scopolamine hydrobromide 30min after the administration of rLZ-8 on the 14th day of experiment, and the space exploration test was conducted 30min after the administration of scopolamine hydrobromide. Compared with that in the normal saline group, the swimming time of the rats' staying in the quadrant of the original platform was decreased in the model group, but there was no significant difference in it between the two groups $(P \otimes 0.05)$, while the steering angle, the number of times passing through the location of the original platform and the number of times passing through the effective area of the original platform were significantly decreased $(P<0.05)$. Compared with that in the model group, the steering angle, the number of times passing through the location of the original platform and the number of times passing through the effective area of the original platform were significantly increased in $112 \mu \mathrm{g} / \mathrm{kg} \mathrm{rLZ-8}$ group $(P<0.05)$, the number of times passing through the location of the original platform and the number of times passing through the effective area of the original platform were significantly increased in $56 \mathrm{ug} / \mathrm{kg} \mathrm{rLZ}-8 \mathrm{group}$ $(P<0.05)$, and the steering angle and the number of times passing through the effective area of the original platform were significantly increased in donepezil group $(P<0.05)$.as shown in Figure 1 and Table 3.

Table 3.

Space exploration test $(\mathrm{s}, \mathrm{x} \pm \mathrm{s})$

\begin{tabular}{|lllll|}
\hline $\begin{array}{l}\text { Groups } \\
(n=10)\end{array}$ & $\begin{array}{l}\text { Time in the } \\
\text { second quadrant }\end{array}$ & $\begin{array}{l}\text { Orientation } \\
\text { angle }\end{array}$ & $\begin{array}{l}\text { Number of passing through the location } \\
\text { of original platform }\end{array}$ & $\begin{array}{l}\text { Number of passing through } \\
\text { the effective area }\end{array}$ \\
\hline $\begin{array}{l}\text { Normal } \\
\text { saline }\end{array}$ & $32.3 \pm 4.89$ & $75.7 \pm 45.07$ & $4.63 \pm 2.12^{\square}$ & $6.63 \pm 1.93^{\square}$ \\
\hline Model & $24.62 \pm 5.81$ & $56.4 \pm 42.64^{\star}$ & $1.14 \pm 3.95^{\star}$ & $4.57 \pm 3.50^{*}$ \\
\hline Donepezil & $31.4 \pm 6.16$ & $76.8 \pm 35.19^{\square}$ & $1.25 \pm 2.22^{*}$ & $6.00 \pm 4.00^{\square}$ \\
\hline $\begin{array}{l}56 \mu g / \mathrm{kg} \\
\mathrm{rLZ}-8\end{array}$ & $38.3 \pm 10.59$ & $67.3 \pm 32.94$ & $2.38 \pm 1.93^{\square}$ & $7.13 \pm 5.97^{\square}$ \\
\hline $\begin{array}{l}112 \\
\mu \mathrm{g} / \mathrm{kg} \\
\mathrm{rLZ}-8\end{array}$ & $28.4 \pm 7.71$ & $85.3 \pm 32.82^{\square}$ & $1.75 \pm 1.79^{\star} \square$ & $6.88 \pm 4.70^{\square}$ \\
\hline $\begin{array}{l}224 \\
\mu \mathrm{g} / \mathrm{kg} \\
\mathrm{rLZ}-8\end{array}$ & $30.4 \pm 2.67$ & $61.3 \pm 31.08$ & $1.38 \pm 1.58^{*}$ & $4.25 \pm 6.61^{*}$ \\
\hline
\end{tabular}

* Compared with the normal saline group, $P<0.05 ;{ }^{\square}$ Compared with the model group, $P<0.05$.

lom the values of the Sco group: $\mathrm{P}<0.05 .{ }^{\# \#}$ Results significantly differ from the values of the Sco group: $P<0.01$.

\section{Biochemical Indexes}

\subsection{Biochemical indexes in the serum of rats}

\subsubsection{Acetylcholinesterase (TChE) activities}

Compared with the normal saline group, the activity of TChE in the serum of rats in the model group was significantly higher $(P<$ 0.01), compared with the model group,the $56 \mu \mathrm{g} / \mathrm{kg}$ rLZ-8 group was significantly lower $(P<0.05)$, and the donepezil group was significantly lower $(P<0.01)$. As shown in Table 4.

\subsubsection{Monoamine oxidase (MAO) activities}

Compared with the normal saline group,the activity of MAO in the serum of rats in the model group was significantly higher $(P<$ 0.01), compared with the normal saline group, the $56 \mu \mathrm{g} / \mathrm{kg}, 112 \mu \mathrm{g} / \mathrm{kg}$ and $224 \mu \mathrm{g} / \mathrm{kg} \mathrm{rLZ}-8$, and donepezil groups was 
significantly higher $(P<0.01)$, compared with the model group, the $56 \mu \mathrm{g} / \mathrm{kg}, 112 \mu \mathrm{g} / \mathrm{kg}$ and $224 \mu \mathrm{g} / \mathrm{kg}$ rLZ-8, and donepezil groups was significantly lower $(P<0.01)$. As shown in Table 4.

Table 4.

TChE and MAO activities in the serum of rats $(s, x \pm s)$

\begin{tabular}{|c|c|c|}
\hline Groups $₫ n=10 \otimes$ & TChE (U/mgprot) & MAO (U/mgprot) \\
\hline Normal saline & $6.633 \pm 0.938$ & $34.930 \pm 1.379$ \\
\hline AD model & $9.434 \pm 1.433^{\star *}$ & $55.737 \pm 1.534^{\star \star}$ \\
\hline Donepezil & $6.934 \pm 1.516^{\square \square}$ & $48.771 \pm 1.806^{\star \star \square]}$ \\
\hline $56 \mu \mathrm{g} / \mathrm{kg}$ rLZ-8 & $6.035 \pm 1.426^{\square}$ & $50.699 \pm 0.543^{* \star \square \square} \Delta \Delta$ \\
\hline $112 \mu \mathrm{g} / \mathrm{kg}$ rLZ-8 & $7.587 \pm 2.009$ & $51.245 \pm 0.329^{* \star \square \square} \triangle \triangle \Delta$ \\
\hline $224 \mu \mathrm{g} / \mathrm{kg}$ rLZ-8 & $7.428 \pm 2.373$ & $51.802 \pm 1.114^{\star \star \Delta \square} \triangle \triangle \Delta$ \\
\hline \multicolumn{3}{|c|}{$\begin{array}{l}{ }^{*} \text { Compared with the normal saline group, } P<0.05 ;{ }^{*} \text { Compared with the normal saline group, } P<0.01 ;{ }^{\square} \text { Compared with the } \\
\text { model group, } P<0.05 ;{ }^{\square} \text { Compared with the model group, } P<0.01 ; \triangle \text { Compared with donepezil group, } P<0.05 ; \triangle \triangle \text { Compared with } \\
\text { donepezil group, } P<0.01 ; \Delta \text { Compared with } 56 \mu \mathrm{g} / \mathrm{kg} \text { rLZ-8 group, } P<0.05 \text {. }\end{array}$} \\
\hline
\end{tabular}

\subsubsection{Superoxide dismutase (SOD) activities}

Compared with the normal saline group, the activity of SOD in the serum of rats in the model group was significantly lower $(P<0.01)$, and the $224 \mu \mathrm{g} / \mathrm{kg}$ rLZ-8 group was significantly lower $(P<0.05)$; compared with the model group, the $56 \mu \mathrm{g} / \mathrm{kg}$ and 112 $\mu \mathrm{g} / \mathrm{kg}$ rLZ-8 groups was significantly higher $(P<0.01)$. As shown in Table 5.

\subsubsection{Glutathione peroxidase (GSH-PX) activities}

Compared with the normal saline group, the activity of GSH-PX in the serum of rats in the model group was significantly reduced $(P<0.01)$, and $56 \mu \mathrm{g} / \mathrm{kg}, 112 \mu \mathrm{g} / \mathrm{kg}$ and $224 \mu \mathrm{g} / \mathrm{kg}$ rLZ-8 groups was significantly reduced $(P<0.01)$; compared with the model group, the $56 \mu \mathrm{g} / \mathrm{kg}, 112 \mu \mathrm{g} / \mathrm{kg}$ and $224 \mu \mathrm{g} / \mathrm{kg} \mathrm{rLZ}-8$ groups was significantly increased $(P<0.01)$, and the donepezil group was also significantly increased $(P<0.01)$. As shown in Table 5 .

\subsubsection{Malondialdehyde (MDA) contents}

Compared with the normal saline group, the content of MDA in the serum of rats in the model group was significantly higher $(P$ $<0.01)$, and $112 \mu \mathrm{g} / \mathrm{kg}$ and $224 \mu \mathrm{g} / \mathrm{kg}$ rLZ-8 groups was significantly higher $(P<0.05)$; compared with the model group, the donepezil and $56 \mu \mathrm{g} / \mathrm{kg}$ rLZ-8 groups $(P<0.01)$, and $112 \mu \mathrm{g} / \mathrm{kg}$ rLZ-8 groups was significantly lower $(P<0.05)$. As shown in Table 5. 
Table 5.

SOD and GSH-PX activities and MDA contents in the serum of rats $(\mathrm{s}, \mathrm{x} \pm \mathrm{s})$

\begin{tabular}{|c|c|c|c|}
\hline Groups $(n=10)$ & SOD (U/mgprot) & GSH-PX (U/mgprot) & $\mathrm{MDA}(\mathrm{nmol} / \mathrm{ml})$ \\
\hline Normal saline & $217.08 \pm 46.61$ & $1844.83 \pm 78.24$ & $2.70 \pm 0.50$ \\
\hline AD model & $134.98 \pm 29.67^{\star \star}$ & $1062.03 \pm 130.22^{\star \star}$ & $5.35 \pm 1.66^{\star *}$ \\
\hline Donepezil & $191.68 \pm 40.53^{\# \#}$ & $1815.10 \pm 44.40^{\# \#}$ & $3.67 \pm 1.21^{\# \#}$ \\
\hline $56 \mu \mathrm{g} / \mathrm{kg}$ rLZ-8 & $225.68 \pm 68.73^{\# \#}$ & $1650.20 \pm 92.15^{\star \star \# \# \triangle \triangle}$ & $4.23 \pm 0.78^{\# \#}$ \\
\hline $112 \mu \mathrm{g} / \mathrm{kg}$ rLZ-8 & $218.26 \pm 78.09^{\# \#}$ & $1538.18 \pm 98.54^{\star \star \# \# \triangle \triangle \Delta}$ & $3.82 \pm 1.22^{\star \#}$ \\
\hline $224 \mu \mathrm{g} / \mathrm{kg}$ rLZ-8 & $165.44 \pm 50.46^{\star} \boldsymbol{\Lambda}$ & $1405.71 \pm 107.40^{\star \star \# \# \triangle \triangle \Delta \Delta}$ & $3.39 \pm 2.03^{*}$ \\
\hline
\end{tabular}

${ }^{*}$ Compared with the normal saline group, $P<0.05$; ${ }^{*}$ Compared with the normal saline group, $P<0.0$; ${ }^{\square}$ Compared with the model group, $P<0.05$; ${ }^{\square}$ Compared with the model group, $P<0.01 ; \triangle$ Compared with donepezil group, $P<0.05 ; \triangle \triangle$ Compared with dopezil group, $P<0.01 ; \mathbf{\Delta}$ Compared with $56 \mu \mathrm{g} / \mathrm{kg}$ rLZ-8 group, $P<0.05$; $\Delta$ \ Compared with $56 \mu \mathrm{g} / \mathrm{kg}$ rLZ-8 group, $P<0.01$.

\subsection{Biochemical indexes in the hippocampus and cerebral cortex of rats}

\subsubsection{Acetylcholinesterase (TChE) activities}

Compared with the normal saline group, the activity of TChE in the hippocampus of rats in model group was significantly higher $(P<0.05)$, and the denepezil and $224 \mu \mathrm{g} / \mathrm{kg}$ rLZ-8 groups was significantly higher $(P<0.05)$; compared with the model group, thedonepezil group was significantly lower $(P<0.05)$, the $56 \mu \mathrm{g} / \mathrm{kg}$ and $112 \mu \mathrm{g} / \mathrm{kg}$ rLZ-8 groups was significantly lower $(P<$ 0.01). As shown in Table 6.

Compared with the normal saline group, the activity of AChE in the cerebral cortex of rats in the model group was significantly higher $(P<0.01)$; compared with the model group,the $56 \mu \mathrm{g} / \mathrm{kg}$ rLZ-8 group was significantly lower than $(P<0.05)$, and the donepezil group was significantly lower $(P<0.01)$. As shown in Table 7.

\subsubsection{Choline acetyltransferase (ChAT) contents}

Compared with the normal saline group, the content of ChAT in the hippocampus of rats was significantly lower in the model group $(P<0.01)$, compared with the model group,the donepezil and $56 \mu \mathrm{g} / \mathrm{kg} \mathrm{rLZ-8} \mathrm{groups} \mathrm{was} \mathrm{significantly} \mathrm{higher}(P<0.01)$. As shown in Table 6.

Compared with the normal saline group, the content of ChAT in the cerebral cortex of rats was significantly lower in the model group $(P<0.05)$, compared with the model group, the The $224 \mathrm{ug} / \mathrm{kg}$ rLZ-8 and donepezil groups was significantly higher $(P<$ $0.05)$, and the $56 \mu \mathrm{g} / \mathrm{kg}$ rLZ-8 group was significantly higher $(P<0.01)$. As shown in Table 7. 
Table 6.

TChE activities and the ChAT contents in the hippocampus of rats $(\mathrm{s}, \mathrm{x} \pm \mathrm{s})$

\begin{tabular}{|c|c|c|}
\hline Groups $(n=10)$ & TChE activities (U/mgprot) & ChAT contents (IU/g) \\
\hline Normal saline & $0.205 \pm 0.055$ & $261.71 \pm 33.37$ \\
\hline AD model & $0.280 \pm 0.137^{*}$ & $167.705 \pm 36.72^{\star \star}$ \\
\hline Donepezil & $0.195 \pm 0.097^{\square}$ & $248.99 \pm 26.62^{\square}$ \\
\hline 56 g/kg rLZ-8 & $0.197 \pm 0.058^{\square}$ & $228.14 \pm 48.04^{\square \square}$ \\
\hline $112 \mu \mathrm{g} / \mathrm{kg}$ rLZ-8 & $0.185 \pm 0.048^{\square \square}$ & $226.27 \pm 74.14$ \\
\hline 224 g/kg rLZ-8 & $0.228 \pm 0.071^{\star} \square$ & $228.54 \pm 121.97$ \\
\hline
\end{tabular}

Table 7.

TChE activities and the ChAT contents in the cerebral cortex of rats $(s, x \pm s)$

\begin{tabular}{|c|c|c|}
\hline Groups $(n=10)$ & TChE activities $₫ \mathrm{U} / \mathrm{mgprot} \rrbracket$ & ChAT contents $\mathbb{I U} / \mathrm{g} \rrbracket$ \\
\hline Normal saline & $0.176 \pm 0.052$ & $243.26 \pm 79.90$ \\
\hline AD model & $0.261 \pm 0.028^{\star \star}$ & $165.80 \pm 58.91^{*}$ \\
\hline Donepezil & $0.180 \pm 0.037^{\square 0}$ & $194.24 \pm 61.06^{\square}$ \\
\hline $56 \mu \mathrm{g} / \mathrm{kg}$ rLZ-8 & $0.197 \pm 0.138^{\square}$ & $172.98 \pm 23.95^{\square \square}$ \\
\hline $112 \mu \mathrm{g} / \mathrm{kg}$ rLZ-8 & $0.222 \pm 0.057$ & $174.78 \pm 57.85$ \\
\hline 224 нg/kg rLZ-8 & $0.242 \pm 0.168$ & $202.59 \pm 63.97^{\square}$ \\
\hline
\end{tabular}

\subsubsection{Superoxide dismutase (SOD) activities}

Compared with the normal saline group, the activity of SOD in the hippocampus of rats decreased significantly in the model group $(P<0.05)$, compared with the model group, the donepezil, $56 \mu \mathrm{g} / \mathrm{kg}, 224 \mu \mathrm{g} / \mathrm{kg}$ rLZ-8 groups was significantly increased $(P$ $<0.01)$. As shown in Table 8.

Compared with the normal saline group, the activity of SOD in the cerebral cortex of rats was significantly lower in the model group $(P<0.01)$ and significantly higher in donepezil group $(P<0.01)$, compared with the model group, the donepezil, $56 \mu \mathrm{g} / \mathrm{kg}$ and $112 \mu \mathrm{g} / \mathrm{kg}$ rLZ-8 groups was significantly higher $(P<0.05)$. As shown in Table 9.

\subsubsection{Glutathione peroxidase (GSH-PX) activities}

Compared with the normal saline group, the activity of GSH-PX in the hippocampus of rats was significantly decreased in the model group $(P<0.01)$ and significantly decreased in $224 \mu \mathrm{g} / \mathrm{kg}$ rLZ-8 group $(P<0.01)$, compared with the model group, the donepezil and $56 \mu \mathrm{g} / \mathrm{kg}$ rLZ-8 groups was significantly increased $(P<0.01)$, and $112 \mu \mathrm{g} / \mathrm{kg}$ rLZ-8 group was significantly increased $(P<0.05)$. As shown in Table 8. 
Compared with the normal saline group, the activity of GSH-PX in the cerebral cortex of rats was significantly lower in the model group $(P<0.05)$, compared with the model group, the $112 \mu \mathrm{g} / \mathrm{kg}$ rLZ-8 group was significantly higher $(P<0.05)$, and the donepezil group was significantly higher $(P<0.01)$. As shown in Table 9.

\subsubsection{Malondialdehyde (MDA) contents}

Compared with the normal saline group, the content of MDA in the hippocampus of rats was significantly increased in the model group $(P<0.01)$, compared with the model group, the donoperazide and $56 \mu \mathrm{g} / \mathrm{kg}$ rLZ-8 groups was significantly lower $(P<0.05)$ ,and the $112 \mu \mathrm{g} / \mathrm{kg}$ rLZ-8 group was significantly lower $(P<0.01)$. As shown in Table 8.

Compared with the normal saline group, the content of MDA in the cerebral cortex of rats was significantly increased in the model group $(P<0.01)$; compared with the model group, the donepezil and $56 \mu \mathrm{g} / \mathrm{kg} \mathrm{rLZ}-8$ groups was significantly decreased $(P$ $<0.05)$, and 112 and $224 \mu \mathrm{g} / \mathrm{kg}$ rLZ-8 groups was significantly decreased $(P<0.01)$. As shown in Table 9.

Table 8.

SOD and GSH-PX activities and MDA contents in the hippocampus of rats $(s, x \pm s)$

\begin{tabular}{|llll|}
\hline Groups $(n=10)$ & SOD (U/mgprot) & GSH-PX (U/mgprot) & MDA (nmol/ml) \\
\hline Normal saline & $85.25 \pm 35.55$ & $38.99 \pm 6.45$ & $0.34 \pm 0.02$ \\
\hline AD model & $51.90 \pm 21.59^{*}$ & $27.64 \pm 5.39^{\star \star}$ & $0.41 \pm 0.02^{\star \star}$ \\
\hline Donepezil & $79.02 \pm 37.40^{\# \#}$ & $35.99 \pm 3.53^{\# \#}$ & $0.34 \pm 0.04^{\#}$ \\
\hline $56 \mu \mathrm{g} / \mathrm{kg} \mathrm{rLZ}-8$ & $63.09 \pm 12.72^{\# \#}$ & $34.49 \pm 1.87^{\# \#}$ & $0.36 \pm 0.02^{\# \#}$ \\
$112 \mu \mathrm{g} / \mathrm{kg} \mathrm{rLZ}-8$ & $58.82 \pm 18.11$ & $33.71 \pm 5.00^{\#}$ & $0.36 \pm 0.03^{\# \#}$ \\
\hline $224 \mu \mathrm{g} / \mathrm{kg} \mathrm{rLZ}-8$ & $58.85 \pm 11.10^{\# \# \triangle}$ & $30.65 \pm 5.30^{\text {**}}$ & $0.35 \pm 0.08$ \\
\hline
\end{tabular}

${ }^{*}$ Compared with the normal saline group, $P<0.05 ;{ }^{* *}$ Compared with the normal saline group, $P<0.01 ;{ }^{\square}$ Compared with the model group, $P<0.05$; ${ }^{\square}$ Compared with the model group, $P<0.01 ; \triangle$ Compared with donepezil group, $P<0.05$; .

Table 9.

SOD and GSH-PX activities and MDA contents in the cerebral cortex of rats $(\mathrm{s}, \mathrm{X} \pm \mathrm{s})$

\begin{tabular}{|c|c|c|c|}
\hline Groups $(n=10)$ & SOD (U/mgprot) & GSH-PX (U/mgprot) & $\mathrm{MDA}(\mathrm{nmol} / \mathrm{ml})$ \\
\hline Noemal saline & $129.58 \pm 14.22$ & $40.65 \pm 9.65$ & $0.90 \pm 0.13$ \\
\hline AD model & $115.21 \pm 17.68^{\star *}$ & $33.64 \pm 17.67^{\star}$ & $1.11 \pm 0.09^{\star \star}$ \\
\hline Donepezil & $135.11 \pm 31.22^{\star \star \# \#}$ & $40.81 \pm 10.10^{\#}$ & $0.91 \pm 0.28^{\#}$ \\
\hline $56 \mu \mathrm{g} / \mathrm{kg}$ rLZ-8 & $137.91 \pm 21.74^{\#}$ & $40.64 \pm 5.12$ & $0.92 \pm 0.41^{\#}$ \\
\hline $112 \mu \mathrm{g} / \mathrm{kg}$ rLZ-8 & $135.23 \pm 25.26^{\#}$ & $36.97 \pm 6.16^{\# \#}$ & $0.94 \pm 0.30^{\# \#}$ \\
\hline 224 pg/kg rLZ-8 & $110.22 \pm 10.21^{\# \triangle \Delta \Delta}$ & $36.54 \pm 3.01 \wedge$ & $0.99 \pm 0.15^{\# \#}$ \\
\hline
\end{tabular}

${ }^{*}$ Compared with the normal saline, $P<0.05 ;{ }^{* \star}$ Compared with the normal saline, $P<0.01$; ${ }^{\square}$ Compared with the model group, $P<0.05$; ${ }^{\square}$ Compared with the model group, $P<0.01 ; \triangle$ Compared with donepezil group, $P<0.05 ; \triangle \triangle$ Compared with donepezil group, $P<0.01$; $\Delta$ Compared with $56 \mu \mathrm{g} / \mathrm{kg}$ rLZ-8 group, $P<0.05$; $\Delta \Delta^{\Delta}$ Compared with $56 \mu \mathrm{g} / \mathrm{kg}$ rLZ-8 group, $P<0.01$.

\subsubsection{Catalase (CAT) activities}


Compared with the normal saline group,the activity of CAT in the hippocampus of rats was significantly lower in the model, donepezil and $112 \mu \mathrm{g} / \mathrm{kg}$ rLZ-8 groups $(P<0.01)$, compared with the model group, the donepezil and $56 \mu \mathrm{g} / \mathrm{kg}$ rLZ-8 a groups was significantly higher $(P<0.01)$, and the $224 \mu \mathrm{g} / \mathrm{kg}$ group was significantly higher $(P<0.05)$. As shown in Table 10.

Compared with the normal saline group,the activity of CAT in the cerebral cortex of rats in the model group was significantly lower $(P<0.05)$, compared with the model group,the donepezil group was significantly higher $(P<0.01)$, and the $56 \mu \mathrm{g} / \mathrm{kg}$ and $112 \mu \mathrm{g} / \mathrm{kg}$ rLZ-8 groups was significantly higher $(P<0.05)$. As shown in Table 11.

\subsubsection{Nitric oxide synthase (NOS) contents}

The contents of TNOS and iNOS in the hippocampus of rats in the model group were significantly higher than those in the normal saline group $(P<0.05)$, the content of iNOS in the hippocampus of rats in donepezil, $56 \mu \mathrm{g} / \mathrm{kg} \mathrm{rLZ}-8$ and $112 \mu \mathrm{g} / \mathrm{kg} \mathrm{rLZ}-8$ groups was significantly lower than that in the model group $(P<0.05)$, and the content of iNOS in $56 \mu \mathrm{g} / \mathrm{kg}$ rLZ-8 group was significantly lower than that in the model group $(P<0.05)$. As shown in Table10 .

The contents of TNOS and iNOS in the cerebral cortex of rats in the model group were significantly higher than those in the normal saline group $(P<0.05)$, and the contents of TNOS and iNOS in donepezil and $56 \mu \mathrm{g} / \mathrm{kg}$ rLZ-8 groups were significantly lower $(P<0.05)$. As shown in Table 11.

Table 10.

TNOS and iNOS contents and CAT activities in the hippocampus of rats $(\mathrm{s}, \mathrm{x} \pm \mathrm{s})$

\begin{tabular}{|llll|}
\hline Groups $(n=10)$ & CAT (U/mgprot) & TNOS (U/mgprot) & iNOS (U/mgprot) \\
\hline Normal saline & $0.637 \pm 0.189$ & $0.982 \pm 0.259$ & $0.577 \pm 0.166$ \\
\hline AD model & $0.264 \pm 0.127^{\star *}$ & $1.237 \pm 0.185^{\star}$ & $0.783 \pm 0.175^{\star}$ \\
\hline Donepezil & $0.411 \pm 0.137^{\star \# \#}$ & $0.987 \pm 0.299^{\#}$ & $0.560 \pm 0.153^{\# \#}$ \\
\hline $56 \mu \mathrm{g} / \mathrm{kg} \mathrm{rLZ}-8$ & $0.562 \pm 0.206^{\# \#}$ & $0.935 \pm 0.213^{\# \#}$ & $0.548 \pm 0.199^{\#}$ \\
\hline $112 \mu \mathrm{g} / \mathrm{kg} \mathrm{rLZ}-8$ & $0.374 \pm 0.170^{\star \star} \star$ & $0.995 \pm 0.283^{\#}$ & $0.608 \pm 0.256$ \\
\hline $224 \mu \mathrm{g} / \mathrm{kg} \mathrm{rLZ}-8$ & $0.627 \pm 0.449^{\#}$ & $1.268 \pm 1.117 \star$ & $0.715 \pm 0.328$ \\
\hline
\end{tabular}

${ }^{*}$ Compared with the normal saline group, $P<0.05$; ${ }^{*}$ Compared with the normal saline group, $P<0.01 ;{ }^{\square}$ Compared with the model group, $P<0.05 ;{ }^{\square}$ Compared with the model group, $P<0.01 ; \mathbf{\Lambda}$ Compared with $56 \mu \mathrm{g} / \mathrm{kg} \mathrm{rLZ}$-8 group, $P<0.05 ; \mathbf{\Lambda}$.

Table 11.

TNOS and iNOS contents and CAT activities in the cerebral cortex of rats (s,

\begin{tabular}{|llll|}
\hline \multicolumn{4}{|c}{$\mathrm{x} \pm \mathrm{s})$} \\
\hline Groups $(n=10)$ & CAT (U/gprot) & TNOS (U/mgprot) & iNOS (U/mgprot) \\
\hline Normal saline & $0.233 \pm 0.125$ & $1.557 \pm 0.329$ & $0.549 \pm 0.198$ \\
\hline Don model & $0.129 \pm 0.038^{*}$ & $1.953 \pm 0.446^{*}$ & $0.794 \pm 0.284^{*}$ \\
\hline $56 \mu \mathrm{g} / \mathrm{kg}$ rLZ-8 & $0.216 \pm 0.082^{\#}$ & $1.446 \pm 0.389^{\#}$ & $0.512 \pm 0.157^{\#}$ \\
\hline $112 \mu \mathrm{g} / \mathrm{kg}$ rLZ-8 & $0.194 \pm 0.073^{\#}$ & $1.715 \pm 0.552$ & $0.711 \pm 0.425$ \\
\hline $224 \mu \mathrm{g} / \mathrm{kg} \mathrm{rLZ}-8$ & $0.178 \pm 0.137$ & $1.757 \pm 0.521$ & $0.732 \pm 0.386$ \\
\hline
\end{tabular}

Page 11/21 
*Compared with the normal saline group, $P<0.05 ;$ Compared with the model group, $P<0.05 ;{ }^{\square}$ Compared with the model group, $P<0.01$.

\section{Cytokines Detected by ELISA}

\subsection{Cytokines in the serum of rats}

\subsubsection{Tumor Necrosis Factor a (TNF-a)}

Compared with the normal saline group, the content of TNF-a in the serum of rats did not change significantly in the model group, but the content of TNF-a increased slightly in the donepezil and rLZ-8-treated groups, showing no difference; compared with $56 \mu \mathrm{g} / \mathrm{kg}$ rLZ-8 group, the $224 \mu \mathrm{g} / \mathrm{kg}$ rLZ-8 group was significantly lower $(P<0.05)$. As shown in Table 12.

\subsubsection{Interleukin 6 (IL-6) contents}

Compared with the normal saline group, the content of IL-6 in the serum of rats was significantly higher in $56 \mu \mathrm{g} / \mathrm{kg}$ rLZ-8 group $(P<0.05)$; compared with $56 \mu \mathrm{g} / \mathrm{kg}$ rLZ-8 group, the $112 \mu \mathrm{g} / \mathrm{kg}$ rLZ-8 group was significantly lower $(P<0.05)$, and the in 224 $\mu \mathrm{g} / \mathrm{kg}$ rLZ-8 group was significantly lower $(P<0.01)$. As shown in Table 12.

\subsubsection{Interlukin $1 \beta(\mathrm{IL}-1 \beta)$ contents}

Compared with that normal saline group, there was no significant change in the content of IL-1 $\beta$ in the serum of rats in the other experimental groups; compared with the model group, the 112 and $224 \mu \mathrm{g} / \mathrm{kg}$ rLZ-8 groups was significantly lower $(P<0.05)$; compared with donepezil group, the $56 \mu \mathrm{g} / \mathrm{kg}$ rLZ-8 group was significantly higher $(\mathrm{P}<0.05)$, and the 112 and $224 \mu \mathrm{g} / \mathrm{kg} \mathrm{rLZ}-8$ groups was significantly lower $(P<0.01)$. As shown in Table 12.

Table 12

TNF- $a$, IL- 6 and IL-1 $\beta$ contents in the serum of rats $(s, x \pm s)$

\begin{tabular}{|c|c|c|c|}
\hline $\operatorname{Groups}(n=10)$ & TNF-a(ng/L) & IL-6 (pg/ml) & $\mathrm{IL}-1 \beta(\mathrm{pg} / \mathrm{ml})$ \\
\hline Normal saline & $294.588 \pm 36.689$ & $113.766 \pm 19.176$ & $48.003 \pm 18.864$ \\
\hline AD model & $294.516 \pm 50.525$ & $127.669 \pm 21.464$ & $52.164 \pm 8.917$ \\
\hline Donepezil & $315.411 \pm 124.049$ & $99.966 \pm 20.388^{\#}$ & $44.949 \pm 11.220$ \\
\hline $56 \mu \mathrm{g} / \mathrm{kg}$ rLZ-8 & $336.733 \pm 51.569$ & $143.790 \pm 32.699^{\star} \triangle$ & $56.551 \pm 9.510^{\triangle}$ \\
\hline $112 \mu \mathrm{g} / \mathrm{kg}$ rLZ-8 & $310.063 \pm 45.082$ & $113.729 \pm 19.594 \Delta$ & $43.736 \pm 6.730^{\# \boldsymbol{\Lambda} \Lambda}$ \\
\hline $224 \mu \mathrm{g} / \mathrm{kg} \mathrm{rLZ}-8$ & $283.463 \pm 39.842^{\Delta}$ & $85.545 \pm 22.363^{\star \# \# \mathbf{\Delta} \boldsymbol{} \S}$ & $39.859 \pm 11.560^{\# \boldsymbol{\Delta} \Delta}$ \\
\hline
\end{tabular}

${ }^{*}$ Compared with the normal group, $P<0.05 ;{ }^{\square}$ Compared with the model group, $P<0.05$; ${ }^{\square}$ Compared with the model group, $P<0.01$;

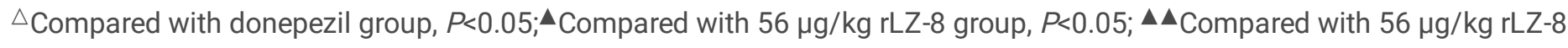
group, $P<0.01$; $\$$ Compared with $112 \mu \mathrm{g} / \mathrm{kg}$ rLZ-8 group, $P<0.05$

\subsection{Cytokines in the hippocampus and cerebral cortex of rats}

\subsubsection{Tumor necrosis factor $a(T N F-a)$ contents}

Compared with the normal saline group, the content of TNF-a in the hippocampus of rats was not significantly different in the other experimental groups, compared with the model group, the $224 \mu \mathrm{g} / \mathrm{kg}$ rLZ-8 group was significantly lower $(P<0.05)$. As 
shown in Table 13.

Compared with the normal saline group, the content of TNF-a in the cerebral cortex of rats was significantly lower in donepezil group $(P<0.01)$, while the other groups was not significantly different; compared with the model group, the donepezil group was significantly reduced $(P<0.01)$; compared with donepezil group, the three groups treated with rLZ-8 was significantly elevated $(P$ $<0.01)$; compared with $56 \mu \mathrm{g} / \mathrm{kg}$ rLZ-8 group, the $112 \mu \mathrm{g} / \mathrm{kg}$ rLZ-8 group was significantly elevated $(P<0.05)$; compared with $112 \mu \mathrm{g} / \mathrm{kg}$ rLZ-8 group, the $224 \mu \mathrm{g} / \mathrm{kg}$ rLZ-8 group was significantly reduced $(P<0.05)$. As shown in Table 14.

\subsubsection{Interleukin 6 (IL-6) contents}

Compared with the normal saline group, the content of IL-6 in the hippocampus of rats was significantly reduced indonepezil and $224 \mu \mathrm{g} / \mathrm{kg}$ rLZ-8 group $(P<0.01)$, and the $56 \mu \mathrm{g} / \mathrm{kg}$ rLZ-8 group was also significantly reduced $(P<0.05)$; compared with the model group, the donepezi and $224 \mu \mathrm{g} / \mathrm{kg}$ rLZ-8 groups was significantly reduced $(P<0.01)$, and $56 \mu \mathrm{g} / \mathrm{kg}$ rLZ-8 group decreased significantly $(P<0.05)$; compared with donepezil, $56 \mu \mathrm{g} / \mathrm{kg}$ rLZ-8 and $112 \mu \mathrm{g} / \mathrm{kg} \mathrm{rLZ}-8$ groups, the $224 \mu \mathrm{g} / \mathrm{kg} \mathrm{rLZ}-8$ group was significantly decreased $(P<0.01)$. As shown in Table 13.

Compared with the normal saline group, the content of IL-6 in the cerebral cortex of rats decreased significantly in 56 and 224 $\mu \mathrm{g} / \mathrm{kg}$ rLZ-8 groups $(P<0.05)$, the other groups did not change significantly $(P \otimes 0.05)$; compared with the model group, the in56 and $224 \mu \mathrm{g} / \mathrm{kg}$ rLZ-8 groups was significantly decreased $(P<0.01)$; compared with $56 \mu \mathrm{g} / \mathrm{kg}$ rLZ-8 group, the $112 \mu \mathrm{g} / \mathrm{kg}$ rLZ-8 group was significantly increased $(P<0.01$ ); compared with $112 \mu \mathrm{g} / \mathrm{kg}$ rLZ-8 group, the $224 \mu \mathrm{g} / \mathrm{kg}$ rLZ-8 group was significantly decreased $(P<0.01)$. As shown in Table 14.

\subsubsection{Interlukin $1 \beta(I L-1 \beta)$ contents}

As shown in Table 13, there was no significant difference in the content of IL-1 $\beta$ in the hippocampus of rats among the different experimental groups;

Compared with the normal saline group, the content of IL-1 $\beta$ in the cerebral cortex of rats was significantly lower in donepezil group $(P<0.01)$; compared with the model group, the donepezil and $56 \mu \mathrm{g} / \mathrm{kg} \mathrm{rLZ-8}$ groups was significantly lower $(P<0.01)$, and in $224 \mu \mathrm{g} / \mathrm{kg}$ rLZ-8 group $(P<0.05)$; compared with donepezil group, the three rLZ-8-treated groups was significantly lower $(P<0.01)$. As shown in Table 14

Table 13.

TNF-a, IL- 6 and IL-1 $\beta$ contents in the hippocampus of rats $(s, x \pm s)$

\begin{tabular}{|c|c|c|c|}
\hline Groups $(n=6)$ & TNF-a (ng/mg) & IL-6 (ng/mg) & $\mathrm{IL}-1 \beta(\mathrm{ng} / \mathrm{mg})$ \\
\hline Normal saline & $3.720 \pm 0.392$ & $5.027 \pm 0.618$ & $0.876 \pm 0.192$ \\
\hline AD model & $3.996 \pm 0.384$ & $5.511 \pm 0.784$ & $1.024 \pm 0.267$ \\
\hline Donepezil & $3.481 \pm 0.473$ & $3.768 \pm 0.428^{\star \star \# \#}$ & $0.762 \pm 0.153$ \\
\hline $56 \mu \mathrm{g} / \mathrm{kg}$ rLZ-8 & $3.482 \pm 0.454$ & $4.258 \pm 0.438^{\star \#}$ & $0.813 \pm 0.053$ \\
\hline $112 \mu \mathrm{g} / \mathrm{kg}$ rLZ-8 & $3.968 \pm 0.818$ & $4.279 \pm 1.057$ & $0.900 \pm 0.199$ \\
\hline $224 \mu \mathrm{g} / \mathrm{kg}$ rLZ-8 & $3.347 \pm 0.285^{\square}$ & $3.102 \pm 0.503^{\star \star \# \# \triangle \triangle \triangle \S \S}$ & $0.848 \pm 0.044$ \\
\hline
\end{tabular}

${ }^{*}$ Compared with the normal saline group, $P<0.05 ;{ }^{*}$ Compared with the normal saline group, $P<0.01 ;{ }^{\square}$ Compared with the model group, $P<0.05 ;{ }^{\square}$ Compared with the model group, $P<0.01 ; \triangle$ Compared with donepezil group, $P<0.05 ; \triangle \triangle$ Compared with donepezil group, $P<0.01$; $\triangle$ Compared with $56 \mu \mathrm{g} / \mathrm{kg}$ rLZ-8 group, $P<0.05$; $\S$ Compared with $112 \mu \mathrm{g} / \mathrm{kg}$ rLZ-8 group, $P<0.05$. 
Table 14.

TNF- $a$, IL- 6 and IL-1 $\beta$ in the cerebral cortex of rats $(s, x \pm s)$

\begin{tabular}{|c|c|c|c|}
\hline Groups $(n=10)$ & TNF-a (ng/mg) & IL-6 (ng/mg) & IL-1ß (ng/mg囚 \\
\hline Normal saline & $3.431 \pm 0.476$ & $4.206 \pm 0.854$ & $0.768 \pm 0.157$ \\
\hline AD model & $3.407 \pm 0.262$ & $5.226 \pm 0.680$ & $0.924 \pm 0.142$ \\
\hline Donepezil & $2.106 \pm 0.159^{\star \star \# \#}$ & $3.506 \pm 0.552^{\#}$ & $0.477 \pm 0.101^{\star \star \# \#}$ \\
\hline $56 \mu \mathrm{g} / \mathrm{kg} \mathrm{rLZ-8}$ & $3.106 \pm 0.341 \triangle \Delta$ & $3.052 \pm 0.456^{\star \# \#}$ & $0.691 \pm 0.057^{\# \# \triangle \triangle}$ \\
\hline $112 \mu \mathrm{g} / \mathrm{kg}$ rLZ-8 & $4.118 \pm 0.849 \triangle \triangle \Delta$ & $4.732 \pm 0.632 \triangle \triangle \Delta \Lambda$ & $0.871 \pm 0.186 \triangle \triangle$ \\
\hline 224 нg/kg rLZ-8 & $3.196 \pm 0.346 \triangle \triangle \S$ & $3.021 \pm 0.090^{\star \# \# \S \S}$ & $0.725 \pm 0.081^{\# \Delta \triangle}$ \\
\hline
\end{tabular}

${ }^{* *}$ Compared with the normal saline group, $P<0.01$; Compared with the model group, $P<0.05 ;{ }^{\square}$ Compared with the model group, $P<0.01 ; \triangle \triangle$ Compared with donepezil group, $P<0.01 ;{ }^{\Delta}$ Compared with $56 \mu \mathrm{g} / \mathrm{kg}$ rLZ-8 group, $P<0.05 ; \Delta \Delta$ Compared with $56 \mu \mathrm{g} / \mathrm{kg}$

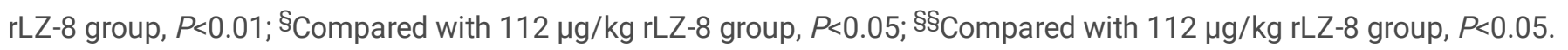

\subsubsection{Glial-derived neurotrophic factor (GDNF) contents}

Compared with the normal saline group, the content of GDNF in the hippocampus of rats the model group was significantly lower than the normal saline group $(P<0.05)$, compared with the model group,the 112 and $224 \mu \mathrm{g} / \mathrm{kg}$ rLZ-8 groups was significantly higher $(P<0.05)$, compared with the $56 \mu \mathrm{g} / \mathrm{kg}$ rLZ-8 group, the $112 \mu \mathrm{g} / \mathrm{kg}$ rLZ-8 group was significantly higher $(P<$ 0.05). As shown in Table 15.

Compared with the normal saline group, the content of GDNF in the cerebral cortex of rats was not significantly different in the other experimental groups, compared with in the model group,the 56 and $224 \mu \mathrm{g} / \mathrm{kg}$ rLZ-8 groups was significantly lower $(P<$ 0.05), compared with the $56 \mu \mathrm{g} / \mathrm{kg}$ rLZ-8 group,the $112 \mu \mathrm{g} / \mathrm{kg}$ rLZ-8 groups was significantly higher $(P<0.05)$, compared with the $112 \mu \mathrm{g} / \mathrm{kg}$ rLZ-8 group,the $224 \mu \mathrm{g} / \mathrm{kg}$ rLZ-8 groups was significantly lower $(P<0.01)$, As shown in Table 16 .

\subsubsection{Brain-derived neurotrophic factor (BDNF) contents}

Compared with the normal saline group, the content of BDNF in the hippocampus of rats in $224 \mu \mathrm{g} / \mathrm{kg}$ rLZ-8 group was significantly higher $(P<0.05))$, compared with the model group,the donepezil group was significantly higher $(P<0.05)$ and the $224 \mu \mathrm{g} / \mathrm{kg}$ rLZ-8 group was significantly higher $(P<0.01)$, compared with the $56 \mu \mathrm{g} / \mathrm{kg}$ rLZ-8 group, the $224 \mu \mathrm{g} / \mathrm{kg}$ rLZ-8 group was significantly higher $(P<0.01)$, compared with the $112 \mu \mathrm{g} / \mathrm{kg}$ rLZ-8 group, the $224 \mu \mathrm{g} / \mathrm{kg}$ rLZ-8 group was significantly higher $(P<0.05)$,As shown in Table 15.

Compared with the normal saline group, the content of BDNF in the cerebral cortex of rats in the model group was significantly lower $(P<0.01)$ and the $112 \mu \mathrm{g} / \mathrm{kg}$ rLZ-8 group was significantly higher $(P<0.01)$; Compared with the model group, the donepezil and $112 \mu \mathrm{g} / \mathrm{kg}$ rLZ-8 groups was significantly increased $(P<0.01)$, and the224 $\mu \mathrm{g} / \mathrm{kg}$ rLZ-8 group was also significantly increased $(P<0.05)$; compared with $112 \mu \mathrm{g} / \mathrm{kg}$ rLZ-8 group, the donepezil, $56 \mu \mathrm{g} / \mathrm{kg}$ rLZ-8 and $224 \mu \mathrm{g} / \mathrm{kg}$ rLZ-8 groups was significantly decreased $(P<0.01)$. As shown in Table 16 
Table 15.

GDNF and BDNF contents in the hippocampus of rats $(s, x \pm s)$

\begin{tabular}{|c|c|c|}
\hline Groups $(n=10)$ & GDNF (ng/mg) & BDNF (ng/mg) \\
\hline Normal saline & $2.537 \pm 0.370$ & $2.942 \pm 0.511$ \\
\hline AD model & $2.145 \pm 0.059^{*}$ & $2.643 \pm 0.326$ \\
\hline Donepezil & $2.313 \pm 0.282$ & $3.384 \pm 0.499^{\square}$ \\
\hline 56 g/kg rLZ-8 & $2.176 \pm 0.117$ & $2.511 \pm 0.232^{\triangle}$ \\
\hline $112 \mu \mathrm{g} / \mathrm{kg}$ rLZ-8 & $2.561 \pm 0.304^{\llbracket \Perp}$ & $3.036 \pm 0.565$ \\
\hline 224 нg/kg rLZ-8 & $2.361 \pm 0.171^{\square}$ & $3.776 \pm 0.352^{* \square \Delta} \mathbf{\Delta} \S$ \\
\hline
\end{tabular}

${ }^{*}$ Compared with the normal saline group, $P<0.05 ; P<0.01 ;{ }^{\square}$ Compared with the model group, $P<0.05$; ${ }^{\square}$ Compared with the model group, $P<0.01 ; \triangle$ Compared with donepezil group, $P<0.05 ; P<0.01 ; \Delta^{\Delta}$ Compared with $56 \mu \mathrm{g} / \mathrm{kg}$ rLZ-8 group, $P<0.05 ; \boldsymbol{\Delta} \Delta_{\text {Compared }}$ with $56 \mu \mathrm{g} / \mathrm{kg}$ rLZ-8 group, $P<0.01$; §Compared with $112 \mu \mathrm{g} / \mathrm{kg}$ rLZ-8group, $P<0.05$;

Table 16.

GDNF and BDNF contents in the cerebral cortex of rats $(\mathrm{s}, \mathrm{x} \pm \mathrm{s})$

\begin{tabular}{|c|c|c|}
\hline Groups $(n=10)$ & GDNF(ng/mg) & $\mathrm{BDNF}(\mathrm{ng} / \mathrm{mg})$ \\
\hline Normal saline & $1.725 \pm 0.462$ & $2.918 \pm 0.131$ \\
\hline AD model & $1.990 \pm 0.109$ & $2.476 \pm 0.155^{\star \star}$ \\
\hline Donepezil & $1.796 \pm 0.099$ & $3.223 \pm 0.298^{\square}$ \\
\hline $56 \mu \mathrm{g} / \mathrm{kg}$ rLZ-8 & $1.801 \pm 0.067^{\square}$ & $2.898 \pm 0.454$ \\
\hline $112 \mu \mathrm{g} / \mathrm{kg}$ rLZ-8 & $2.312 \pm 0.269 \triangle \boldsymbol{\Delta}$ & $4.166 \pm 0.204^{* \star \square] \triangle \triangle \Delta \Delta}$ \\
\hline 224 нg/kg rLZ-8 & $1.675 \pm 0.127^{\square \S \S}$ & $2.885 \pm 0.159^{\square \S \S}$ \\
\hline
\end{tabular}

${ }^{*}$ Compared with the normal saline group, $P<0.01 ;{ }^{\square}$ Compared with the model group, $P<0.05 ;{ }^{\square}$ Compared with the model group, $P<0.01 ; \triangle$ Compared with donepezil group, $P<0.05 ; \triangle \triangle$ Compared with donepezil group, $P<0.01 ; \triangle$ Compared with $56 \mu \mathrm{g} / \mathrm{kg} \mathrm{rLZ}-8$

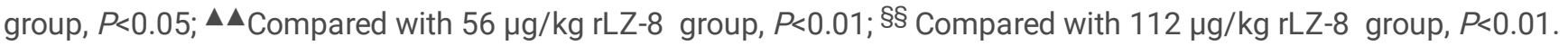

\section{Organ Indexes}

Compared with the normal saline group, the thymus index of rats in the model group decreased significantly $(P<0.05)$, and there was no significant difference in the other organ indexes between the normal saline group and model group ( $P \otimes 0.05)$, indicating that scopolamine hydrobromide had no significant effect on the index of organs except the thymus. Compared with the normal saline group, the lung index and the spleen index of rats increased significantly in $56 \mu \mathrm{g} / \mathrm{kg}$ rLZ-8 group $(P<0.05)$, the spleen index decreased significantly in $112 \mu \mathrm{g} / \mathrm{kg}$ rLZ-8 group $(P<0.05)$, and the spleen index increased significantly in $224 \mu \mathrm{g} / \mathrm{kg} \mathrm{rLZ}-$ 8 group $(P<0.05)$. Compared with that in the model group, the lung index, the spleen index and the thymus index increased significantly in $56 \mu \mathrm{g} / \mathrm{kg}$ rLZ-8 group $(P<0.05)$, the spleen index decreased significantly in $112 \mu \mathrm{g} / \mathrm{kg}$ rLZ-8 group $(P<0.05)$, and the spleen index and the thymus index increased significantly in $224 \mu \mathrm{g} / \mathrm{kg}$ rLZ-8 group $(P<0.05)$. After the administration of scopolamine hydrobromide for one week, its effects on the organ indexes of rats were not significant, but the administration of 
different dosages of scopolamine hydrobromide for two weeks showed some effects on the spleen and thymus of rats because an immunomodulatory protein could regulate the immune system to a certain extent, suggesting that the changes in the immune organ indexes of rats during the experiment should be a manifestation of the regulation of the rats' autoimmunity system. As shown in Table 17.

Table 17.

Organ indexes $(s, x \pm s)$

\begin{tabular}{|c|c|c|c|c|c|c|}
\hline \multicolumn{7}{|l|}{ Groups $(n=10)$} \\
\hline & Normal saline & Model & Donepezil & $56 \mu \mathrm{g} / \mathrm{kg}$ rLZ-8 & $112 \mu \mathrm{g} / \mathrm{kg}$ rLZ-8 & $224 \mu \mathrm{g} / \mathrm{kg} \mathrm{rLZ}-8$ \\
\hline Heart index & $0.33 \pm 0.007$ & $0.36 \pm 0.004$ & $0.35 \pm 0.004$ & $0.34 \pm 0.004$ & $0.33 \pm 0.005$ & $0.34 \pm 0.004$ \\
\hline Liver index & $3.75 \pm 0.067$ & $3.51 \pm 0.045$ & $3.58 \pm 0.060$ & $3.60 \pm 0.050$ & $3.64 \pm 0.055$ & $3.54 \pm 0.055$ \\
\hline Lung index & $0.44 \pm 0.004$ & $0.43 \pm 0.004$ & $0.47 \pm 0.006$ & $0.49 \pm 0.009^{\star \square}$ & $0.45 \pm 0.004$ & $0.50 \pm 0.019$ \\
\hline Spleen index & $0.23 \pm 0.001$ & $0.23 \pm 0.001$ & $0.26 \pm 0.001$ & $0.28 \pm 0.001^{\star \star}$ & $0.20 \pm 0.001^{\text {* }}$ & $0.41 \pm 0.002^{\star \rrbracket}$ \\
\hline Thymus index & $0.19 \pm 0.001$ & $0.16 \pm 0.001^{*}$ & $0.19 \pm 0.001$ & $0.21 \pm 0.001^{\square}$ & $0.19 \pm 0.001$ & $0.24 \pm 0.001^{\square}$ \\
\hline Kidney index & $0.71 \pm 0.010$ & $0.71 \pm 0.007$ & $0.70 \pm 0.010$ & $0.68 \pm 0.017$ & $0.70 \pm 0.006$ & $0.68 \pm 0.012$ \\
\hline
\end{tabular}

* Compared with the normal saline group, $P<0.05 ;{ }^{\square}$ Compared with the model group, $P<0.05$.

\section{Discussion}

Ganoderma lucidum, a traditional Chinese medicine, can improve the oxygen supply ability of hemoglobin, reduce the consumption of invalid oxygen, accelerate the blood circulation, and improve the oxygen supply and nutritional status of the brain, delaying the aging of the brain and showing a certain preventive effect on Alzheimer's disease. Fungal Immunomodulatory Protein of Ganoderma lucidium ( LZ-8), an active component of Ganoderma lucidum, was obtained by genetic engineering in our previous studies. In this study, the protective effects of recombinant Ganoderma lucidum immunomodulatory protein (rLZ-8) against the scopolamine-induced Alzheimer's disease in rats were studied.

Water maze was designed by Morris, a British cardiologist, in the early 1980s for observing the spatial learning and memory ability of experimental animals ${ }^{[18]}$. The results in this study showed that rLZ-8 and donepezil could significantly improve the learning and memory impairment induced by scopolamine hydrobromide, and the improvement of $56 \mu \mathrm{g} / \mathrm{kg} \mathrm{rLZ}-8$ on the learning and memory was better than that of the other doses of rLZ-8. Learning and memory is closely associated with the cholinergic system in basal forebrain (BF) and the content of acetylcholine in the brain tissue decreases with age.

Acetylcholinesterase is a key enzyme to hydrolyze acetylcholine, indirectly reflecting the content of acetylcholine, choline acetyltransferase is a key enzyme that coacts with acetylcholinesterase to regulate the content of acetylcholine in the central nervous system, and acetylcholinesterase together regulate the content of acetylcholine in the body. The results in this study were consistent with those reported by other scholars ${ }^{[18,19]}$. In this study, We found that the activities of acetylcholinesterase and choline acetyltransferase were associated with the dose of rLZ-8, and a low dose of rLZ-8 could significantly improve the learning and memory impairment induced by scopolamine hydrobromide. Free radical damage is the pathological basis of many diseases, and induced mainly by the uncontrollable and abnormal free radical reaction in cells, resulting in serious damages to the structure and function of cells, and free radicals are toxic products that are produced by organisms and can damage themselves, causing lipid peroxidation to produce lipid peroxides. The results in this study showed that the oxygen free radicals were scavenged to some extent in rats in the different rLZ-8-treated groups. NO (nitric oxide) as a vasoactive factor and a special neurotransmitter in the brain is involved in regulating the physiological process of cerebral blood flow, and learning and memory. The contents of total TNOS andiNOS were detected in this experiment, and the results showed that the different doses of rLZ-8 could regulate the activity of NOS enzyme and improve the learning and memory of rats with Alzheimer's disease. 
Some progress has been made in the study on the pathogenesis of inflammatory injury in AD in recent years ${ }^{[20-22]}$. The deposition of AP (amyloid protein) in the brain of AD patients can lead to the excessive secretion of inflammatory cytokines, complement and immune factors by glial cells, thus causing a strong neurotoxic effect. A large number of studies have found that there is a serious focal inflammatory reaction in the brain of patients with $A D$, in which pre-inflammatory factors such as IL$1 \beta, I L-6$ and TNF-a are closely related to the pathogenesis and progression of AD, and TNF- $\alpha$ is the earliest and important inflammatory mediator in the process of inflammatory reaction to activate neutrophils and lymphocytes, increase the permeability of vascular endothelial cells, regulate the metabolism of other tissues, and promote the synthesis and release of other cytokines ${ }^{[23,24]}$. IL-6 can induce the differentiation of B cells to produce antibodies, as well as the activation, proliferation and differentiation of $\mathrm{T}$ cells to participate in the immune response of the body, which is a provocative agent of inflammatory reaction. IL-1, also known as lymphocyte-stimulating factor, is mainly produced by activated monocytes-macrophages, and exists in the forms of IL-1 $\alpha$ and IL-1 $\beta$. The inflammation caused by the interaction of inflammatory factors is also one of the causes of Alzheimer's disease. The increased expression of inflammatory factors can activate microglia to engulf foreign bodies so as to improve the symptoms of Alzheimer's disease. In this study, the expression of inflammatory cytokines IL-1 $1 \beta$, IL- 6 and TNF-a in the hippocampus and cerebral cortex was affected by the different doses of rLZ-8. GDNF is a neurotrophic factor discovered in 1993, the target of GDNF is not only dopaminergic neurons in substantia nigra, but also cholinergic neurons in basal forebrain, and GDNF can reduce the dependence of basal cholinergic neurons on nerve growth factor and is closely related to many degenerative diseases of the nervous system, such as amyotrophic lateral sclerosis (AIS) and $A D^{[25,26]}$. BDNF is one of the members of neurotrophic family ${ }^{[2]}$, widely distributed in the central nervous system, sensory nerve and spinal cord neurons, and is an important neurotrophic factor in neurons and glia; BDNF is closely associated with learning and memory, and the expression of BDNF in the hippocampus plays an important role in strengthening the memory process and long-term potentiation ${ }^{[28,29]}$. The decrease of BDNF in AD can weaken the function of hippocampus in two ways: one is the plasticity of synapses, that is, the deficiency of BDNF can weaken the ability of synapses to encode information and block the long-term potentiation, and the other is that the decrease of BDNF makes hippocampal neurons more vulnerable to damage and degeneration from the point of view of neurotrophic factor, mainly affecting the cholinergic system of basal forebrain. In this experiment, the different doses of rLZ-8 showed a certain effect on the expression of GDNF and BDNF in the hippocampus and cerebral cortex of rats with AD.

\section{Limitations}

In this study, we used scopolamine hydrobromide to induce AD rat model. Scopolamine hydrobromide can bind to choline receptor and block the binding of acetylcholine receptor, resulting in the decrease of acetylcholine transmitter level and the decrease of learning ability. However, the AD rat model induced by scopolamine hydrobromide is a transient model, and it lacks typical pathological changes such as degeneration of ad neurons and deposition of a $\beta$. In this experiment, the learning and memory ability of rats was evaluated by water maze test. The changes of cholinergic system level, antioxidant level, lipid peroxidation level and proinflammatory cytokines in serum, hippocampus and cortical tissue were detected by using the kit. The results showed that rlz-8 could improve the learning ability of transient AD rat model, but not from the water of signal pathway Objective to study the protective mechanism of rlz-8 on scopolamine induced $A D$ rats. In the next step, we have established a rat model of ad induced by D-galactose. On the basis of previous studies, we intend to study the effect of rlz-8 on AD rat model from the level of pathology and signal pathway.

\section{Conclusion}

The above results indicate that rLZ-8 has some advantages over donepazil, because the immunomodulatory protein with less toxic and side effects on human body is different from donepezil, and moreover, rLZ-8 can be used for the prevention of learning and memory impairment for a long time, while donepezil can be only used for the treatment of mild to moderate learning and memory impairment, and can th be used for the prevention of learning and memory impairment.

It was found in our study that rLZ-8 showed some effects on the content or expression of acetylcholinesterase, choline acetyltransferase, various oxygen free radicals, NO, IL-1 1 , IL-6, TNF- $a$, and GDNF in the serum and brain tissues of scopolamine- 
induced $A D$ rats. The change of content or expression of BDNF in serum or brain tissue has certain effect. The mechanism of the protective effect of rLZ-8 against the scopolamine-induced AD in rats is to be investigated at the signal pathway level in our further study.rLZ-8 had no effect on the body weight of rats, but a significant effect on the organ indexes, indirectly suggesting that rLZ-8 had no significant toxic and side effect on rats with AD induced by scopolamine. RLZ-8 could significantly improve the learning and memory impairment of $A D$ rats induced by scopolamine. In addition, rLZ-8 could improve the content or activity of related indexes, which may provide evidences for the results of behavioral experiments, and a basis for the study of rLZ-8 as a drug for the treatment of $A D$.

\section{Abbreviations}

AD: Alzheimer's disease;

rLZ-8: recombinant Ganoderma lucidum immunomodulatory protein

BF: basal forebrain; TChE: Acetylcholinesterase;

ChAT:choline acetyltransferase; MAO: monoamine oxidase ;

SOD: superoxide dismutase; GSH-PX: glutathione peroxidase;

MDA:malondialdehyde; TNF-a: tumor necrosis factor-a;

IL-6: interleukin-6; IL-1 $\beta$ : interleukin- $\beta$;

GDNF: glial-derived neurotrophic factor;

BDNF: brain-derived neurotrophic factor

\section{Declarations}

\section{Ethics approval and consent to participate}

All procedures involing Wistar rats were reviewed and approved by the Institutional Animal Care and Use Committee of Jilin University School of Pharmaceutical Science

\section{Consent for publication}

Not applicable

\section{Availability of data and material}

The datasets use and/or analyzed during the current study are available from the corresponding author on reasonable request

\section{Competing interests}

All the authors declare that they have no competing interests

\section{Funding}

This work was supported by the members of the Development and Reform Commission of Jilin Province for their fund assistance. Subsidy Fund No:2014N149

\section{Authors' contributions}

Jun Fu,Huan Tang and Yan Li prepared the animal model of Alzheimer's in Wistar rats.Liping Song, Dan Xu, Qiang Hao and Qianwen Li performed the Morris water maze test,Training test and Space exploration test.Zhihui Ren, Xiaowei Zhou, Hongyu 
Chen, Weitao Zhao and Juan Jia performed the detection of biochemical indexes.Jin Pei and Fei Sun designed the study.Jin Pei ,Haotian Wang and Jun Fu analyzed the data,and wrote the manuscript. All the authors have read and proofread the final draft of the manuscript.

\section{Acknowledgements}

Not applicable

\section{References}

1. Cooke, K. R., Kobzik, L. , Martin, T. R. , Brewer, J. , Ferrara, J. L. M, Ferrara J L, 1996. An experimental model of idiopathic pneumonia syndrome after bone marrow transplantation: i. the roles of minor $\mathrm{h}$ antigens and endotoxin. Blood. 88, 32303239.

2. Khoury R., Patel K., Gold J., Hinds S., Grossberg GT., 2017. Recent Progress in the Pharmacotherapy of Alzheimer's Disease. Drugs \& Aging. 34, 811-820.

3. Porsteinsson AP., Antonsdottir IM., 2017. An update on the advancements in the treatment of agitation in Alzheimer's disease. Expert Opinion on Pharmacotherapy. 18, 611-620.

4. Glynn-Servedio, B. E. , \& Ranola, T. S. ,2017. Ache inhibitors and nmda receptor antagonists in advanced alzheimer's disease. The Consultant pharmacist. 32, 511-518.

5. Liu M., Jevtic S., Markham-Coultes K., Ellens NPK., O'Reilly MA., Hynynen K., Aubert I., McLaurin J., 2018. Investigating the efficacy of acombination A $\beta$-targeted treatment in a mouse model of Alzheimer's disease. Brain Res. 1678, 138-145.

6. Braidy, N. , Behzad, S. , Habtemariam, S. , Ahmed, T. , Daglia, M. , Nabavi, S. M. ,Sobarzo-Sanchez E, Nabavi SF. , 2017. Neuroprotective effects of citrus fruit-derived flavonoids, nobiletin and tangeretin in alzheimer"s and parkinson"s disease. CNS \& Neurological Disorders - Drug Targets. 16, 387-397.

7. Zeng Q., Zhou F., Lei L., Chen J., Lu J., Zhou J., Cao K., Gao L., Xia F., Ding S., Huang L., Xiang H., Wang J., Xiao Y., Xiao R., Huang J., 2017. Ganoderma lucidum polysaccharides protect fibroblasts against UVB-induced photoaging. Molecular Medicine Reports. 15, 111-116.

8. Yang Z., Chen C., Zhao J., Xu W., He Y., Yang H., Zhou P., 2018. Hypoglycemic mechanism of a novel proteoglycan, extracted from, Ganoderma lucidum, in hepatocytes. European Journal of Pharmacology. 820, 77-85.

9. Wang J., Cao B., Zhao H., Feng J., 2017. Emerging Roles of Ganoderma Lucidum in Anti-Aging. Aging Dis. 8, 691-707.

10. Kino K., Yamashita A., Yamaoka K., Watanabe J., Tanaka S., Ko K., Shimizu K., Tsunoo H., 1989. Isolation and characterization of a new immunomodulatory protein, ling zhi-8 (LZ-8), from Ganoderma lucidium. Journal of Biological Chemistry. 264, 472-478.

11. Liang C , Zhang S , Liu Z , et al. Ganoderma lucidum immunomodulatory protein(LZ-8) expressed in Pichia pastoris and the identification of immunocompetence.[J]. Chinese Journal of Biotechnology, 2009, 25(3):441-447.

12. Lin, J. W. , Hao, L. X. , Xu, G. X. , Sun, F. , Gao, F. , Zhang, R. , 2009. Molecular cloning and recombinant expression of a gene encoding a fungal immunomodulatory protein fromganoderma luciduminpichia pastoris. World Journal of Microbiology \& Biotechnology, 25(3), 383-390.

13. Liang C., Li H., Zhou H., Zhang S., Liu Z., Zhou Q., Sun F., 2012. Recombinant Lz-8 from Ganoderma lucidum induces endoplasmic reticulum stress-mediated autophagic cell death in SGC-7901 human gastric cancer cells. Oncology Reports. 27, 1079-1089.

14. Zhou H., Sun F., Li H., Zhang S., Liu Z., Pei J., Liang C., 2013. Effect of recombinant Ganoderma lucidum immunoregulatory protein on cyclophosphamide-induced leukopenia in mice. Immunopharmacol Immunotoxicol. 35, 426-433.

15. Zhang X., Sun F., Liu Z., Zhang S., Liang C., 2013. Recombinant Ganoderma lucidum immunomodulatory protein modified with polyethylene glycol. Molecular Medicine Reports. 7, 975-980.

16. Shi J., Liu Q., Wang Y., Luo G., 2010. Coadministration of huperzine A and ligustrazine phosphate effectively reverses scopolamine-induced amnesia in rats. Pharmacology. Biochemistry and Behavior. 96, 449-453. 
17. Ahmed T., Gilani AH., 2009. Inhibitory effect of curcuminoids on acetylcholinesterase activity and attenuation of scopolamine-induced amnesia may explain medicinal use of turmeric in Alzheimer's disease. Pharmacology, Biochemistry and Behavior. 91, 554- 559.

18. Alikatte KL., Akondi BR., Yerragunta VG., Veerareddy PR., Palle S., 2012. Antiamnesic activity of Syzygium cumini against scopolamine induced spatial memory impairments in rats. Brain and Development. 34, 844-851.

19. Hasselmo, M. E., 2006. The role of acetylcholine in learning and memory. Current Opinion in Neurobiology. 16, 710-715.

20. Kinney JW., Bemiller SM., Murtishaw AS., Leisgang AM., Salazar AM., Lamb BT., 2018. Inflammation as a central mechanism in Alzheimer's disease. Alzheimers Dement (N Y). 4, 575-590.

21. Parbo P., Ismail R., Hansen KV., Amidi A., Mårup FH., Gottrup H., Brændgaard H., Eriksson BO., Eskildsen SF., Lund TE., Tietze A., Edison P., Pavese N., Stokholm MG., Borghammer P., Hinz R., Aanerud J., Brooks DJ., 2017. Brain inflammation accompanies amyloid in the majority of mild cognitive impairment cases due to Alzheimer's disease. Brain. 140, $2002-2011$.

22. Fujikawa R., Higuchi S., Nakatsuji M., Yasui M., Ikedo T., Nagata M., Hayashi K., Yokode M, Minami M., 2017. Deficiency in ep4 receptor-associated protein ameliorates abnormal anxiety-like behavior and brain inflammation in a mouse model of alzheimer disease. The American Journal of Pathology. 187, 1848-1854.

23. Sawikr Y., Yarla NS., Peluso I., Kamal MA., Aliev G., Bishayee A., 2017. Neuroinflammation in Alzheimer's Disease: The Preventive and Therapeutic Potential of Polyphenolic Nutraceuticals. Advances in Protein Chemistry and Structural Biology. $108,33-57$.

24. Alasmari, F. , Alshammari, M. A. , Alasmari, A. F. , Alanazi, W. A. , Alhazzani, K. , 2018. Neuroinflammatory cytokines induce amyloid beta neurotoxicity through modulating amyloid precursor protein levels/metabolism. BioMed Research International. 2018, 1-8.

25. Brambilla, L. , Guidotti, G. , Martorana, F. , Iyer, A. M. , Aronica, E. , Valori, C. F. , Rossi D., 2016. Disruption of the astrocytic tnfr1-gdnf axis accelerates motor neuron degeneration and disease progression in amyotrophic lateral sclerosis. Human Molecular Genetics. 25,3080-3095.

26. Li B., Gao Y., Zhang W., Xu JR., 2017. Regulation and effects of neurotrophic factors after neural stem cell transplantation in a transgenic mouse model of Alzheimer disease. Journal of Neuroscience Research. 96, 828-840.

27. Numakawa T., Odaka H., Adachi N., 2018. Actions of Brain-Derived Neurotrophin Factor in the Neurogenesis and Neuronal Function, and Its Involvement in the Pathophysiology of Brain Diseases. Int J Mol Sci. 19, 3650.

28. Avgan N., Sutherland HG., Spriggens LK., Yu C4, Ibrahim O., Bellis C., Haupt LM., Shum DH., Griffiths LR.., 2017. BDNF Variants May Modulate Long-Term Visual Memory Performance in a Healthy Cohort. International Journal of Molecular Sciences. 18, 655 .

29. Hu W., Feng Z., Xu J., Jiang Z., Feng M., 2019. Brain-derived neurotrophic factor modified human umbilical cord mesenchymal stem cells-derived cholinergic-like neurons improves spatial learnin. Brain Res. 1710, 61-73.

\section{Figures}




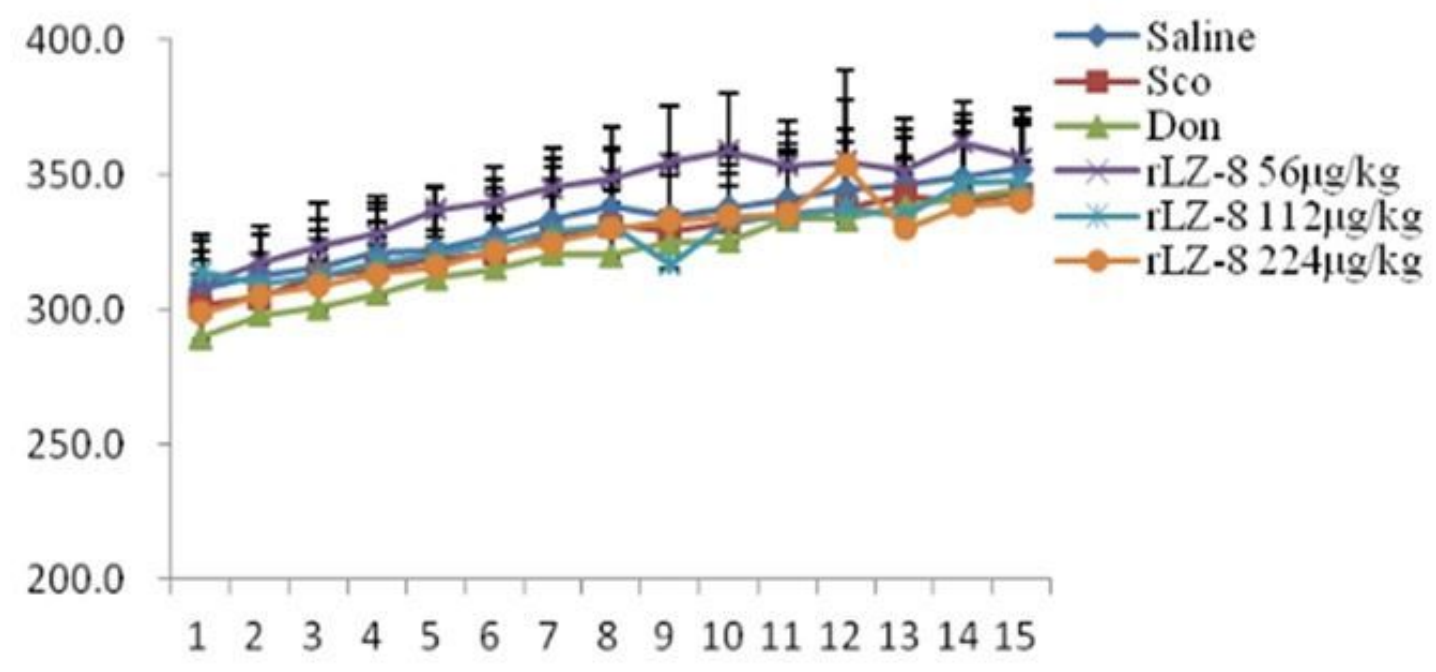

Figure 1

Effects of rLZ-8 on the body weight rats.

a
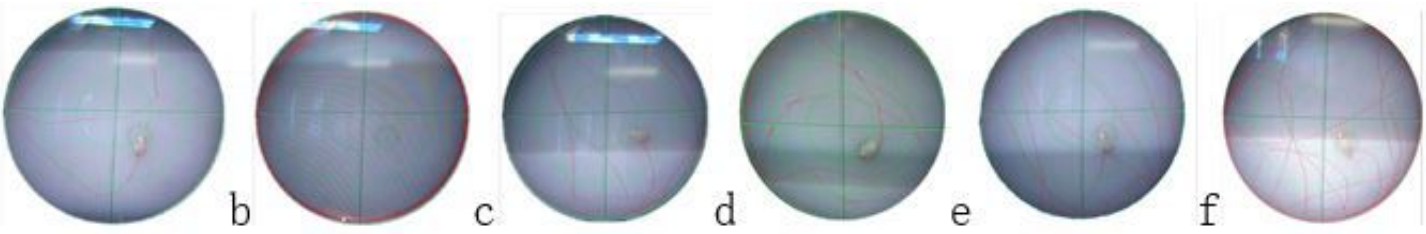

Figure 2

Space exploration test a. Normal saline group; b. AD model group; c. Donepezil group; d. 56 $\mu \mathrm{g} / \mathrm{kg}$ rLZ-8 group; e. $112 \mu \mathrm{g} / \mathrm{kg} \mathrm{rLZ}-8$

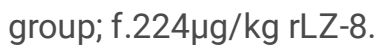

